\title{
A new feature: special issues
}

Plant Cell Reports introduces a new feature: Special issues focussing on topics that merit special attention. Selected original articles, timely reviews and, where appropriate, opinion papers highlight exciting new advances and provide a synthetic view of representative facets of the topic. The special issue thus offers a snapshot of the forefront of our understanding and the state-of-the-art technology in the field.

Modern approaches to plant cell biology rely on the integration of the most advanced concepts and technology from several disciplines in order to understand fundamental principles and functions in plant physiology and development. This first special issue focuses on plant organelle research, which is a good illustration of this multi-disciplinary effort.
Our special recognition goes to Federica Brandizzi and Robert Mullen for their being very instrumental in the preparation of this special issue on 'Organelle biogenesis and communication in plant cells' and for introducing the subject.

Ralf Reski

Reviews Editor

Michael Horn

Günther Hahne

Editors-in-Chief 